\title{
First Report of Colletotrichum Arbiculare Causing Anthracnose in Cucumber
}

\author{
Shanaz Yousuf*, G.H. Dar, Shubana Bhat and Farhanaz Rasool \\ Sher-e Kashmir University of Agricultural Sciences and Technology, Shalimar, \\ Srinagar, India \\ *Corresponding author
}

\begin{abstract}
A B S T R A C T
Keywords

Colletotrichum arbiculare,

Cucumber, Fungus, Anthracnose

Article Info

Accepted:

06 July 2018

Available Online:

10 August 2018

Cucumber (Cucumis sativa) is grown worldwide but suffers from several production constraints including frequent occurrence of diseases. Anthracnose (Colletotrichum orbiculare) is serious disease which infects all the aerial parts of cucumber plant and is reported for the first time in Kashmir. Under humid conditions, the lesions become dotted with pinkish masses of conidia and are manifested as angular to roughly circular reddish brown lesions on leaves. Under humid conditions the lesions become dotted with pinkish masses of conidia. Conidia are mostly produced singly and occasionally in chains at the tip of conidiophores acrogenously. The pathogen (Colletotrichum orbiculare) was successfully isolated from the infected leaves. The culture was raised on oat meal agar for growth and development. The pathogenicity of fungus was successfully established. The detailed morphological characters of the isolated pathogen are reported.
\end{abstract}

Anthracnose, like symptoms were noticed on cucumber vines in Shalimar Srinagar (Jammu and Kashimr) in the month of June 2011. The initial symptoms appeared as roughly circular slightly chlorotic pin-head spots which turned light brown near the veins. The symptomatic variations observed in the lesions formed during the course of infection by the pathogen varied from irregular and jagged to extensive and dark-reddish coloured with grayish centers showing acervulli with dark brown setae followed by cracking of lesions and distortion of leaves towards the vague of July. The centre of lesion was cracked, dropped out and gave shot hole like appearance The average lesion size was 7.5 to $9.0 \mathrm{~mm}$ reaching to a maximum of $1.5 \mathrm{~cm}$ with $3-5$ acervulli/leaf lesion. For pathogenicity test, the fungus was studied both on host as well as in culture. The fungus showed slow growth on oat meal agar medium. The culture was initially white coloured with sparse aerial mycelial growth. The mycelium was hyaline, septate and branched with hypha of 3.2-(3.77)$4.8 \mu \mathrm{m}$ width. Acervulli were formed 3 weeks after vegetative growth in culture. However, no mycelial growth was seen on host. The pathogen formed acervulli in culture as well as on the adaxial surface of infected cucumber leaves. Acervulli were salmon coloured, slightly raised and saucer-shaped with 1-3 hair-like black setae which measured 12.8- 
(33.9) -70.4 × 1.6-(5.5)-6.4 $\mu \mathrm{m}$ in size on host and 12.8-(43.9)-73.6 × 1.6-(5.1)-9.6 $\mu \mathrm{m}$ in culture. Conidia were hyaline, oblong, ovate and single celled and measured 3.2-(6.0)$6.4 \times 3.2(5.1)-6.4 \mu \mathrm{m}$ in size on host and 3.2(6.1)-9.6 $\times$ 3.2-(3.63)-4.8 $\mu \mathrm{m}$ in size in culture. The identity of the pathogens was
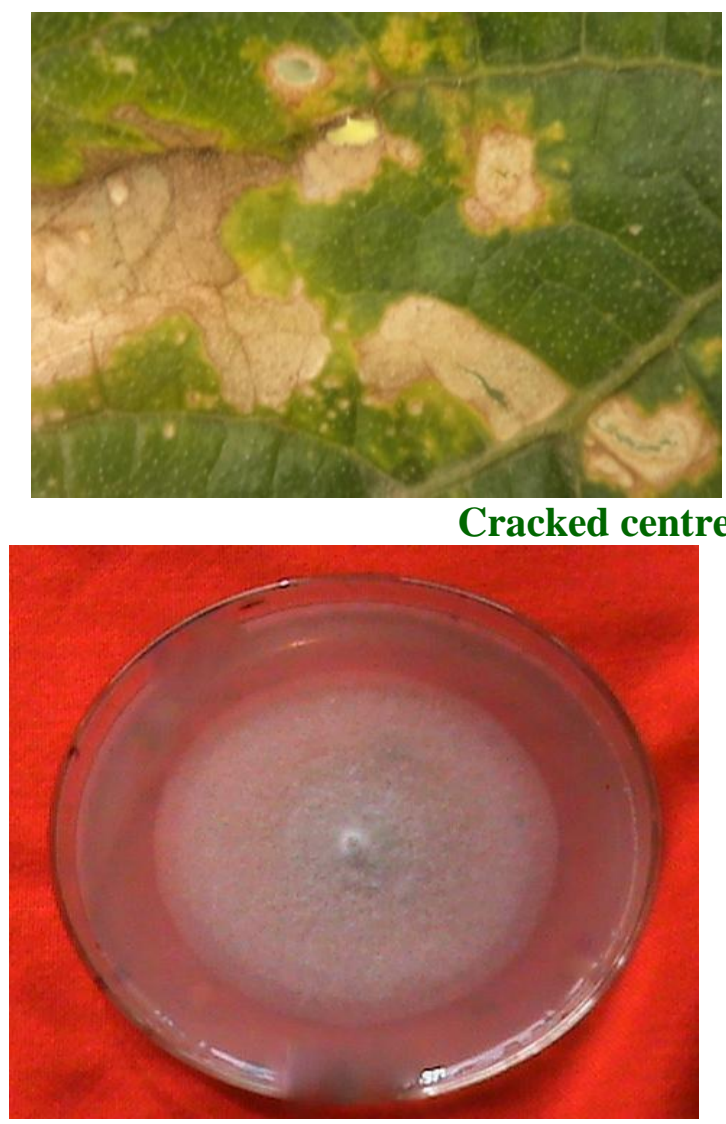

Fungal colony further confirmed at Indian Type Collection Centre under the I.D. No. 9282.14. A respectively while as, Similar descriptions of acervulli and hyphae have been given by Cano et al., (2004), Kumar and Hyde, (2004), Photita et al., (2004) and Agrios (2005).

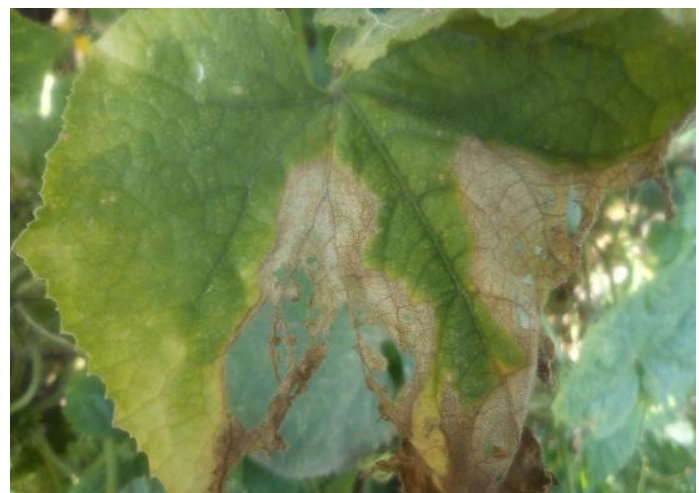

Distorted leaves

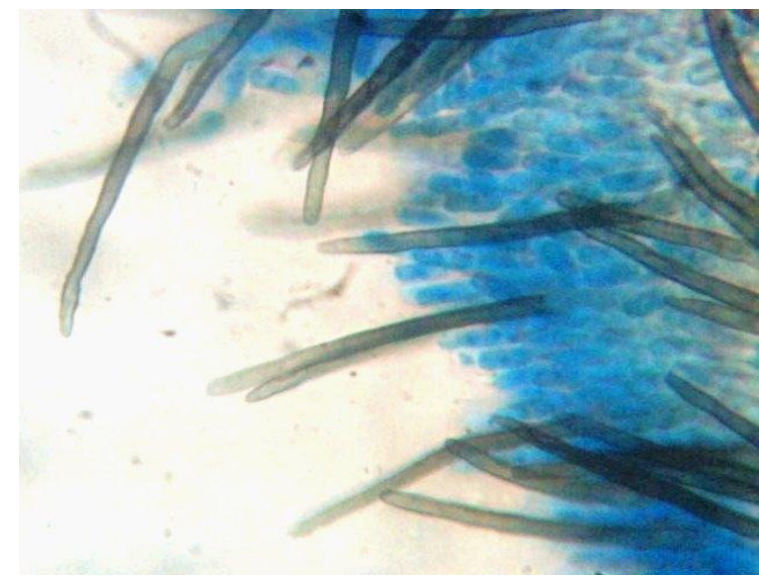

Acervulli with setae

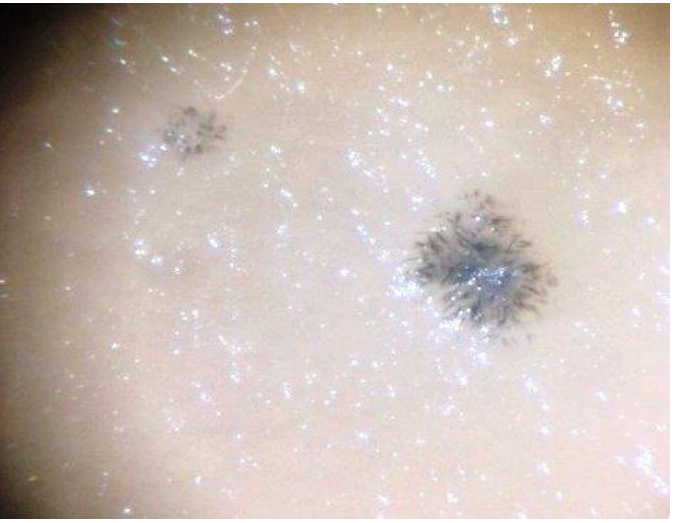

Acervuli in culture 


\section{References}

Agrios, G.N. 2005. Plant Pathology. $5^{\text {th }}$ Edition, Elsevier Academic Press, USA, pp 903.

Cano, J., Guarro, J. and Gene, J. 2004. Molecular and morphological identification of Colletotrichum species of clinical interest. Journal of Clinical Microbiology 42(6): 24502454.

Chawda, S. K., Sabalpara, A. N. and Pandya, J. R. 2012. Epidemiology of turmeric (Curcuma longa) leaf spot caused by
Colletotrichum gloeosporioides (Penz and Sacc). The Bioscan. 7(2): 441443.

Kumar, D.S.S. and Hyde, K.D. 2004. Biodiversity and tissue recurrence of endophytic fungi in Tripterygium wilfordii. Fungal Diversity 17: 69-90.

Photita, W., Lumyong, S., Lumyong, P., Mckenzie, E.H.C. and Hyde, K.D. 2004. Are some endophytes of Musa acuminata latent pathogens? Fungal Diversity 16: 131-140.

\section{How to cite this article:}

Shanaz Yousuf, G.H. Dar, Shubana Bhat and Farhanaz Rasool. 2018. First Report of Colletotrichum Arbiculare Causing Anthracnose in Cucumber. Int.J.Curr.Microbiol.App.Sci. 7(08): 857-859. doi: https://doi.org/10.20546/ijcmas.2018.708.096 